LETTER TO JMG

\title{
Novel lamin A/C gene (LMNA) mutations in atypical progeroid syndromes
}

\author{
A B Csoka, H Cao, P J Sammak, D Constantinescu, G P Schatten, R A Hegele
}

J Med Genet 2004;41:304-308. doi: 10.1136/jmg.2003.015651

$\mathrm{H}$ utchinson-Gilford Progeria Syndrome (HGPS, OMIM 176670), commonly called "progeria", occurs in $\approx 1$ in 8 million births and displays striking features of "premature aging". ${ }^{2}$ HGPS recapitulates most of the pathologies of normal aging at an accelerated rate, with sparing of the nervous system. ${ }^{3}$ Children with HGPS usually appear normal in early infancy, but at about six months of age begin to experience profound growth delay. ${ }^{4}$ Scalp hair, eyebrows, and eyelashes are typically lost resulting in total alopecia. $^{5}$ A gradual, almost complete lipodystrophy begins in infancy, and the skin acquires an abnormally aged appearance with prominent veins. In some children osteolysis may affect the clavicles, terminal phalanges, and acetabulum, and sometimes even more severe bone deformities occur, ${ }^{6}$ including generalised osteoporosis leading to repeated fractures $^{7}$ and degenerative joint changes leading to coxa valga and hip dislocation. ${ }^{8}$ Affected children as young as five years develop widespread atherosclerosis including the coronary arteries and aorta, ${ }^{9}$ often resulting in death by myocardial infarction or stroke in the early teens. ${ }^{10}$ Recently, the genetic basis for HGPS was shown to be heterozygosity for a de novo point mutation in LMNA codon 608 in exon 11 (c. $1824 \mathrm{C}>\mathrm{T}$ ). ${ }^{11-13}$ This single base substitution partially activates a cryptic splice site, leading to an altered lamin A protein in which 50 amino acids near the carboxyl terminus are deleted. The LMNA gene codes for both lamin A and lamin $\mathrm{C}$, but the mutation only affects the structure of lamin A because exon 11 of LMNA is not present in lamin C mRNA.

HGPS is a recent member of the family of "laminopathies", disorders caused by mutations in LMNA. ${ }^{14}{ }^{15}$ Others include autosomal dominant (AD) and autosomal recessive (AR) Emery-Dreifuss muscular dystrophy type 2 (EDMD2), a form of AD dilated cardiomyopathy (CMDIA), AD Dunnigan-type familial partial lipodystrophy, $\mathrm{AD}$ limb girdle muscular dystrophy type IB (LGMDIB), AR Charcot-Marie-Tooth disorder type 2Bl and AR mandibuloacral dysplasia (MAD). Most HGPS probands are heterozygous for LMNA G608G, but one atypical HGPS proband was found to have an E145K mutation $^{12}{ }^{13}$ and one patient was a compound heterozygote for R471C and R527C mutations. ${ }^{11}$ Furthermore, a small subset of patients with features of the adult-onset premature aging disease Werner's syndrome (WRN, OMIM 277700) but no mutations in the causative WRN/RECQL2 gene, ${ }^{16}$ were found to have novel heterozygous LMNA mutations. ${ }^{17}$ MAD has previously been considered as a progeroid disorder, ${ }^{18}{ }_{19}$ and so far one mutation in LMNA has been associated with this disease: R527H. ${ }^{20}$ Therefore, we decided to search for mutations in LMNA in atypical cases of HGPS as well as in other patients with features of premature aging.

\section{MATERIALS AND METHODS}

\section{Study subjects and cell lines}

Thirteen cell lines of patients were obtained from Coriell Cell Repositories (Camden, NJ, USA http://locus.umdnj.edu/ccr/)

\section{Key points}

- Hutchinson-Gilford Progeria Syndrome (HGPS), a "premature aging" disease, is caused by dominant mutations in LMNA encoding lamin A/C. Typical probands are heterozygous for a point mutation (G608G) in LMNA, which leads, by altered splicing, to an abnormally truncated version of lamin $A$, which we term the "progerin" isoform.

- Thirteen cell lines of atypical progeroid patients were obtained from Coriell Cell Repositories (Camden, NJ, USA), selected based on the search terms "atypical progeria" or "progeroid" phenotype. By genomic PCR followed by direct sequencing, we identified three novel heterozygous LMNA mutations in three probands: one patient with atypical HGPS (R644C), another with severe Werner's syndrome (E578V), and a third with Seip syndrome (T10I).

- The T10l and R644C mutations are the most $5^{\prime}$ and $3^{\prime}$ missense mutations in LMNA identified to date.

- The R644C mutation was previously reported in dilated cardiomyopathy and may represent pleiotropy causing different phenotypes.

- Fibroblasts from these three probands had abnormal nuclear membrane architectures characterised by the blebbing or rupture seen in other laminopathies.

- These patients extend the spectrum of abnormal phenotypes caused by LMNA mutations, which may complicate the clinical diagnosis of some patients with laminopathies, but suggest that LMNA is a good candidate for evaluation in patients with other atypical progeria phenotypes.

selected based on the search terms "atypical progeria" or "progeroid" phenotype: AG00989, AG00990, AG01178, AG03364, AG03829, AG04110, AG05233, AG08467, AG11572, AG12795, AG12799, AG15693, and AG15695. The University of Western Ontario ethics review panel had approved the study.

\section{Genomic sequencing}

Established methods were used to extract genomic DNA from cell lines. ${ }^{21}$ All coding exons, plus $>50 \mathrm{bp}$ of intron-exon

Abbreviations: $A D$, autosomal dominant; $A R$, autosomal recessive; CMD1A, a form of AD dilated cardiomyopathy; EDMD2, Emery-Dreifuss muscular dystrophy type 2; HGPS, Hutchinson-Gilford Progeria Syndrome; LGMD 1B, AD limb girdle muscular dystrophy type 1B; MAD, AR mandibuloacral dysplasia; WRN, Werner's syndrome 
boundaries and $>500 \mathrm{bp}$ of $5^{\prime}$ and $3^{\prime}$ untranslated flanking regions of the LMNA gene were sequenced on a Prism 377 Automated DNA Sequencer (PE-Applied Biosystems, Mississauga, ON, Canada) using PCR amplification followed by direct genomic sequencing as described previously. ${ }^{11}$ Mutations were identified using Sequence Navigator software (PE-Applied Biosystems, Mississauga, ON, Canada). Mutation-containing exons were subsequently screened in samples from 100 clinically normal white subjects, to determine whether any observed genomic variant was also present in the normal population.

\section{Immunofluorescence microscopy}

To examine the nuclear morphology of the three mutant cell lines, cultured fibroblasts were plated onto glass coverslips in 6 well plates and grown to approximately 50\% confluency. The cells were fixed in $-20^{\circ} \mathrm{C}$ methanol for 20 minutes at room temperature and then made permeable by incubating with $0.1 \%$ Triton X-100. Non-specific antibody cross reactivity was blocked by a 30 min pre-incubation in a block solution consisting of phosphate buffered saline with $5 \%$ goat serum and $0.3 \%$ bovine serum albumin. Cells were then incubated at room temperature for one hour at $37^{\circ} \mathrm{C}$ with the $\mathrm{H}-110$ primary rabbit polyclonal IgG antibody specific to Lamin A/C (Santa Cruz Biotechnology, Santa Cruz) diluted 1:100 in block solution. Cells were then incubated for one hour at $37^{\circ} \mathrm{C}$ with a secondary goat anti-rabbit antibody conjugated with green fluorescent dye (Alexa Fluor ${ }^{\circledR} 488$ goat anti-rabbit IgG, Molecular Probes, USA) at 1:100 dilution and Toto-3 (Molecular Probes, USA) at 1:1000 dilution in block solution. The coverslips were then mounted on glass slides in a drop of Vectashield mounting medium (Vector Laboratories, Burlingame, CA, USA). A fibroblast cell line derived from a normal donor, GM00038C was used as a control for the immunofluorescence studies. Immunofluorescence microscopy was performed on a Perkin Elmer Ultraview LCS scanning disk confocal head with a Nikon 2000E microscope. Images were acquired with a $60 \times$ planapo objective which provided a transverse resolution of $0.17 \mu \mathrm{m}$ and slice thickness of $0.17 \mu \mathrm{m}$. Image stacks through nuclei were obtained and midsection slices were selected to show lamin $\mathrm{A} / \mathrm{C}$ intensity in laminae cross sections and in the interior of the nucleus. Image staining and acquisition on all samples was done in parallel to minimise artefacts due to variations in staining and illumination. Representative cross section intensity profiles (lines 10 pixels wide) were prepared on confocal slices of nuclear mid sections. Laminae in fibroblasts had equivalent immunostaining intensities.

\section{RESULTS}

\section{Mutational screening}

Out of 13 cell lines from subjects with "atypical progeria", three had missense mutations in LMNA compared to 0/100

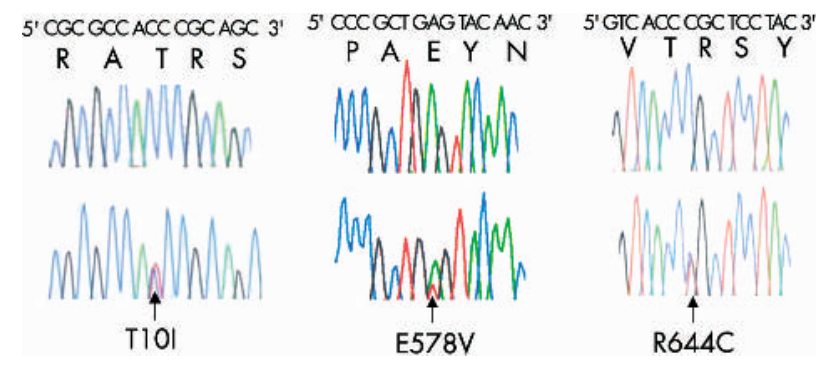

Figure 1 Three new LMNA mutations in subjects with atypical progeria. The sequence traces of the three new mutations we identified are shown. A, subject AG00990: T10I (ACC >ATC); B, subject AG041 10: E578V (GAG>GTG); C, subject AG00989: R644C (CGC>TGC). normal control subjects ( $\mathrm{p}=0.0012$, Fisher's exact test), as shown in fig 1. Subjects AG00989, AG00990, and AG04110 were simple heterozygotes for LMNA missense mutations designated as R644C, T10I, and E578V respectively. All three mutations affected residues in LMNA that are conserved in vertebrates (data not shown). The T10I and R644C mutations are the most $5^{\prime}$ and $3^{\prime}$ missense mutations in LMNA identified to date, with both occurring in the $\mathrm{N}$-terminal head and C-terminal domains of lamin A/C respectively (but with R644C affecting only Lamin A). A diagrammatic representation of the location of the three mutations, along with previously identified mutations causing HGPS, MAD, and atypical WRN can be seen in fig 2 .

\section{Genotype phenotype correlations and pleiotropy}

The clinical attributes for the three carriers of LMNA mutations identified from the screening experiments are shown in table 1 . Each subject had some clinical features that were atypical for classical HGPS. For instance, the original diagnosis for the patient corresponding to cell line AG04110 could not be distinguished between either severe WRN or mild HGPS, and in retrospect the rationale for classifying the patient as WRN was weak. The confounding features included an older age of onset, with some features such as atrophic skin changes, short stature, beak nose and high pitched voice that were common to both HGPS and WRN. The patient corresponding to cell line AG00989 was diagnosed with "atypical progeria" and was noted to have an unspecified type of cachectic dwarfism. However, he had attained an age that was greater than the median age of mortality for HGPS.

The two "atypical progeria" patients with mutant LMNA also expressed components of non-progeroid laminopathies. In particular, the patient corresponding to cell line AG00990, with the T10I mutation, had originally been diagnosed with "atypical progeria", but was later reclassified as "Seip syndrome" based on generalised lipoatrophy and abnormal metabolic biochemical analyses, including elevated triglyceride concentrations and an abnormal glucose tolerance testreminiscent of features seen in lipodystrophy associated with LMNA. ${ }^{21}$ Thus, some of the diseases caused by LMNA mutations may be difficult to classify because of overlapping phenotypic components. The R644C mutation seen in subject AG00989 has previously been reported in a case of CMDIA, ${ }^{22}$ and may be an example of a pleiotropic LMNA mutation of variable penetrance causing different disease phenotypes. R644 is part of the putative cleavage recognition sequence (RSY $\downarrow$ LLG) for the prelamin A endoprotease, Zmpste24, ${ }^{23}{ }^{24}$ and the R644C mutation may inhibit the activity of this enzyme. We hypothesise that the pleiotropy of the R644C mutation may be caused by genetic polymorphism in the ability of Zmpste $24^{23}$ or other endoproteases ${ }^{24}$ to cleave prelamin A. A comprehensive search of the literature revealed that pleiotropy is not unprecedented for LMNA mutations, but has been hitherto unrecognised. For example, the R377H mutation causes both $\mathrm{CMDlA}^{25}$ and $\mathrm{LGMDlB},{ }^{26} \mathrm{Rl33P}$ is causative for both $\mathrm{CMDIA}^{27}$ and EDMD2, ${ }^{28}$ and R133L is causative for both atypical $\mathrm{WRN}^{17}$ and a complex phenotype encompassing lipodystrophy, cardiomyopathy, liver steatosis and skin lesions. ${ }^{29}$ Polymorphisms in prelamin A endoproteases cannot account for these other examples of pleiotropy, for which we postulate the existence of other modifier loci.

\section{Immunofluorescence microscopy}

Aberrations of nuclear morphology have been reported in all of the laminopathies, ${ }^{15}{ }^{30}$ and the three fibroblast cell lines in which we found new LMNA mutations (AG00989, AG00990, AG04110) had a significant proportion of abnormal nuclei characterised by an irregularly shaped nuclear envelope 


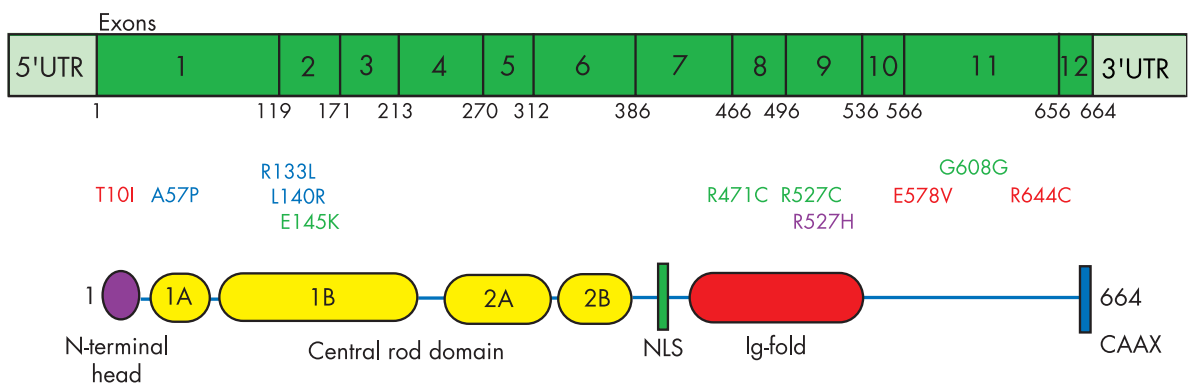

Figure 2 Schematic representation of all "progeroid" mutations in LMNA identified to date. The 12 exons of the LMNA gene are shown in the upper part of the diagram (UTR, untranslated region), with the corresponding domains of the Lamin A protein in the lower part (NLS, nuclear localisation signal; CAAX, prenylation motif). The G608G and E145K mutations causing HGPS ${ }^{11-13}$ and the R471C and R527C mutations ${ }^{13}$ are shown in green. MAD has previously been considered to be a progeroid disorder ${ }^{18}{ }^{19}$ and the causative R527H mutation ${ }^{20}$ is shown in purple. The three mutations (A57P, R133L, and L140R) found in the atypical WRN subjects ${ }^{17}$ are shown in blue. The three new mutations documented in this report (T10I, E578V, and R644C) are shown in red.

(fig 3). There was variation in the severity of nuclear aberration between the three cell lines. Fibroblast line AG00989 had somewhat mildly irregular nuclei (fig 3: AC), AG00990 had grossly abnormal nuclei (fig 3: D-F) and AG04110 had intermediate nuclear irregularities (fig 3: G-I). We found that not all nuclei were abnormal in the mutant cell lines, and some abnormal nuclei were found in the control cell line, as reported previously. ${ }^{13}$ Therefore we scored the percentage of abnormal nuclei $(\mathrm{n}=100)$ in each cell line and obtained the following results: AG00989, 33\%; AG00990, 92\%; AG04110, 42\%; and the control fibroblast GM00038C, $19 \%$. By far the most irregularly shaped nuclei were found in cell line AG00990 (fig 3: D-F), which has the T10I mutation. A high percentage of nuclei in this cell line had multiple, extreme lobulations of the nuclear membrane, resembling somewhat a cauliflower or a bunch of grapes (fig 3: D-F). Some of these lobulations contained no chromatin as revealed by the merging of Toto-3 and Lamin A/C staining (fig $3 \mathrm{~F}$ ), indicating that the lamina had detached from the chromatin. This mutation affects both lamins $\mathrm{A}$ and $\mathrm{C}$ in the $\mathrm{N}$-terminal head domain, and apparently has dramatic consequences for nuclear morphology, perhaps by disrupting lamin polymerisation, a hypothesis that we are investigating.

\section{DISCUSSION}

How do different LMNA mutations produce a spectrum of abnormal phenotypes, including HGPS? The LMNA gene products, lamins A and $\mathrm{C}$, are components of the nuclear lamina, which together with nuclear membranes and pore complexes comprise the nuclear envelope. It seems unlikely that the various laminopathies are caused simply by increased nuclear fragility, primarily because the irregularly shaped nuclear envelopes reported here and elsewhere do not correlate to any specific disease phenotype, or even to disease severity. However, mutations in lamins might adversely influence cell division since the lamina becomes depolymerised during mitosis ${ }^{31}$ and proper lamin organisation is essential for the transition from initiation to elongation during DNA synthesis in S phase..$^{32}$ Secondly, specific nuclear lamin mutations could modify interactions with particular transcription factors, with different effects in different tissues. For example lamin A is already known to interact

\begin{tabular}{|c|c|c|c|c|}
\hline Cell line & $\begin{array}{l}\text { Age, ethnicity, } \\
\text { and sex }\end{array}$ & Diagnosis & Clinical features & LMNA mutation \\
\hline AG00990 & $\begin{array}{l}15 \text { year old } \\
\text { white } \\
\text { male }\end{array}$ & Seip syndrome & $\begin{array}{l}\text { hypertriglyceridemia } \\
\text { hyperglycemia } \\
\text { thinned skin } \\
\text { lipoatrophy } \\
\text { progeroid features }\end{array}$ & $\mathrm{T} 10 \mathrm{l}$ heterozygote \\
\hline AG04110 & $\begin{array}{l}13 \text { year old } \\
\text { white } \\
\text { female }\end{array}$ & $\begin{array}{l}\text { Severe WRN or } \\
\text { mild HGPS }\end{array}$ & $\begin{array}{l}\text { short stature } \\
\text { dysmorphic facies } \\
\text { thinned skin } \\
\text { clinodactyly } \\
\text { beaked nose } \\
\text { high-pitched voice } \\
\text { scoliosis }\end{array}$ & E578V heterozygote \\
\hline AG00989 & $\begin{array}{l}20 \text { year old } \\
\text { white } \\
\text { male }\end{array}$ & $\begin{array}{l}\text { "Atypical } \\
\text { progeria" }\end{array}$ & $\begin{array}{l}\text { short stature } \\
\text { generalised wasting } \\
\text { thinned skin } \\
\text { survival to relatively older age }\end{array}$ & R644C heterozygote \\
\hline
\end{tabular}



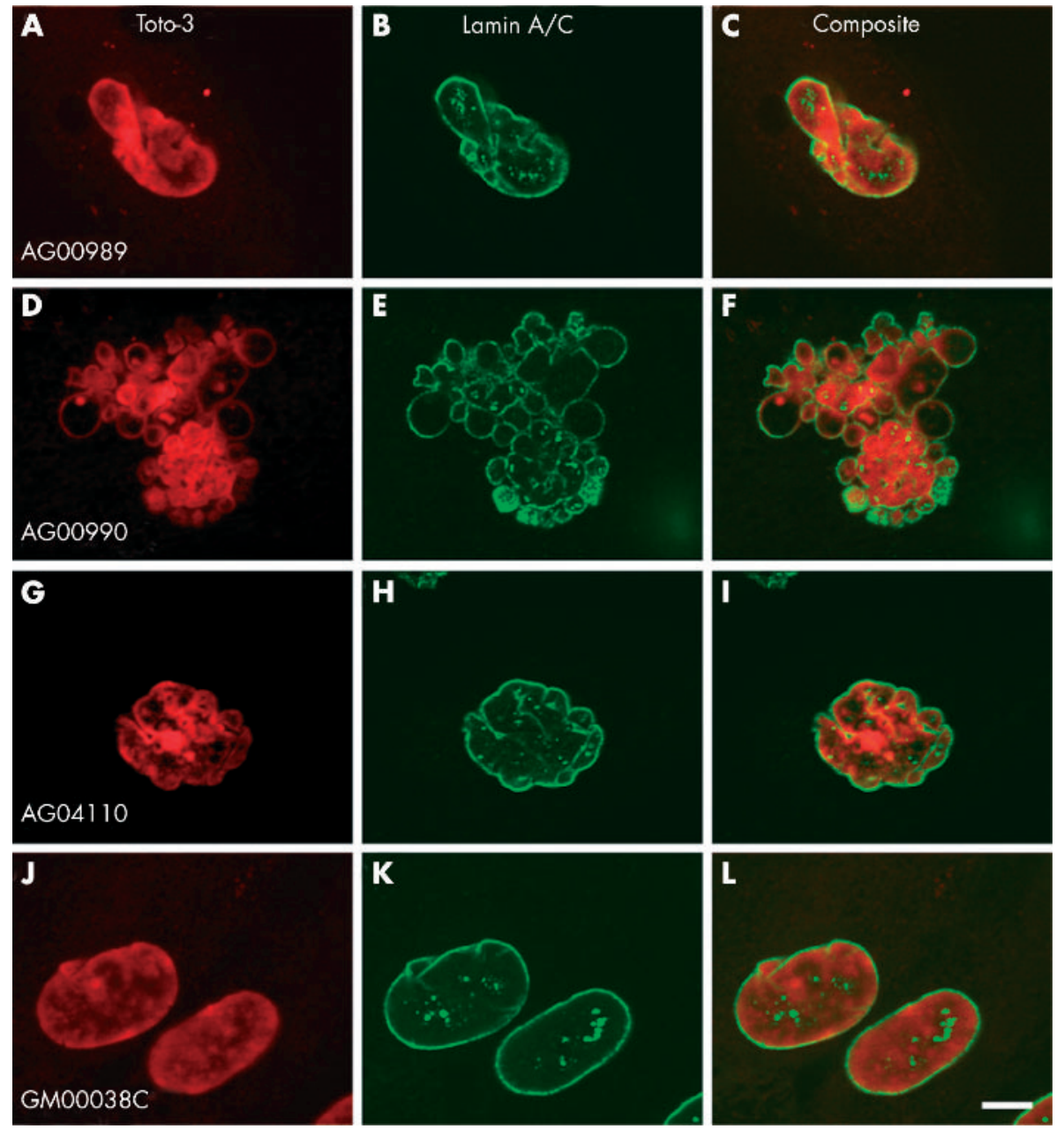

Figure 3 Representative nuclear morphologies of the three mutant fibroblast strains and one control. The left column (panels $A, D, G, J$ ) shows nuclear DNA stained with Toto-3 (Molecular Probes, USA), the middle column (panels B, E, H, K) shows cells stained with the Lamin A/C specific polyclonal antibody H-1 10 (Santa Cruz Biotechnology), and the right column (panels C, F, I, L) is a composite of Toto-3 and Lamin A/C staining. AG00989: A-C, AG00990: D-F, AG041 10: G-I, GM00038C: J-L. All panels are shown at the same scale and image intensity, with a scale bar of $20 \mu \mathrm{m}$ shown at the bottom right of panel $\mathrm{L}$.

with the retinoblastoma $(\mathrm{Rb})$ transcription factor, ${ }^{33}{ }^{34}$ which is involved in controlling various cellular processes such as cell cycle arrest and apoptosis. ${ }^{35}$ Lamin A mutations could have more general, widespread effects on gene expression since proper lamin organisation is essential for RNA polymerase II dependent transcription. ${ }^{36}$ Thirdly, mutant lamins might disrupt the chromatin organisation that is probably essential for preserving fundamental cellular attributes. We postulate that the wide variation in phenotypes of the laminopathies could be explained by the divergent impacts that different mutations have on the tertiary structure of Lamin A and its subsequent interactions within chromatin domains and with global transcriptional regulators. Consequences might vary between tissues depending on the rescue of these functions by other proteins.

Defining LMNA mutation as the causative gene for HGPS, atypical WRN, and now some cases of atypical progeria, not only permits molecular diagnosis and counselling in HGPS families, but also provides a new candidate for evaluation in patients with atypical progeroid syndromes. Dynamic or static nuclear imaging might also be used to permit assignment of numerous idiopathic diseases into the category of laminopathies. While DNA diagnosis of a specific progeroid syndrome may have only limited clinical value at present, future therapies might depend upon having a precise molecular classification.

\section{ACKNOWLEDGEMENTS}

We thank Dr Robert D Goldman and Dr Dale K Shumaker for maintaining cell lines and providing helpful advice. Ms Christina Williams and Ms Monica Carter provided excellent technical assistance.

\section{Authors' affiliations}

A B Csoka, P J Sammak, D Constantinescu, G P Schatten, Pittsburgh Development Center, Magee-Womens Research Institute, Department of Obstetrics, Gynecology \& Reproductive Sciences, University of Pittsburgh School of Medicine, Pittsburgh, PA 15213, USA

H Cao, R A Hegele, Blackburn Cardiovascular Genetics Laboratory, Robarts Research Institute, London, Ontario, Canada

This work was supported by grants from Canadian Institutes for Health Research (MT13430), the Canadian Genetic Diseases Network and the Blackburn Group to RAH, and NIH support to GPS and the Pittsburgh Development Center.

Dr Hegele holds a Canada Research Chair (Tier I) in Human Genetics and a Career Investigator award from the Heart and Stroke Foundation of Ontario. 
Correspondence to: Robert A Hegele, MD, FRCPC, FACP, Blackburn Cardiovascular Genetics Laboratory, Robarts Research Institute, 406100 Perth Drive, London, Ontario, Canada N6A 5K8; hegele@robarts.ca

Received 17 October 2003

Revised version received 17 November 2003

Accepted for publication 18 November 2003

\section{REFERENCES}

1 Hutchinson J. Case of congenital absence of hair, with atrophic condition of the skin and its appendages, in a boy whose mother had been almost wholly bald from alopecia areata from the age of six. Lancet 1886;1:923.

2 Gilford $\mathbf{H}$. Ateleiosis and progeria: continuous youth and premature old age. Br Med J 1904;2:914-8.

3 Fossel M. Human aging and progeria. J Pediatr Endocrinol Metab 2000;13(suppl 6):1477-81.

4 Brown WT. Progeria: a human disease model of premature aging. Am J Clin Nutr 1992;55(suppl 6):1222-4S

5 Jansen T, Romiti R. Progeria infantum (Hutchinson-Gilford syndrome) associated with scleroderma-like lesions and acro-osteolysis: a case report and brief review of the literature. Pediatr Dermatol 2000;17:282-5.

6 De Paula Rodriguez GH, das Eiras Tamege I, Duque G, Spinola Dias Neto V. Severe bone changes in a case of Hutchinson-Gilford syndrome. Ann Genet 2002;45:151-5.

7 Fernandez-Palazzi F, McLaren AT, Slowie DF. Report on a case of Hutchinson-Gilford progeria, with special reference to orthopedic problems. Eur J Pediatr Surg 1992;2:378-82.

8 Gamble JG. Hip disease in Hutchinson-Gilford progeria syndrome. J Pediatr Orthop 1984;4:585-9.

9 Baker PB, Baba N, Boesel CP. Cardiovascular abnormalities in progeria. Case report and review of the literature. Arch Pathol Lab Med 1981;105:384-6.

10 DeBusk FL. The Hutchinson-Gilford progeria syndrome. Report of four cases and review of the literature. J Pediatr 1972;80:697-724.

$11 \mathrm{Cao} \mathrm{H}$, Hegele RA. LMNA is mutated in Hutchinson-Gilford progeria (MIM 176670 ) but not in Wiedemann-Rautenstrauch progeroid syndrome (MIM 264090). J Hum Genet 2003;48:271-4.

12 De Sandre-Giovannoli A, Bernard R, Cau P, Navarro C, Amiel J, Boccaccio I, Lyonnet S, Stewart CL, Munnich A, Le Merrer M, Levy N. Lamin A truncation in Hutchinson-Gilford progeria. Science 2003;300:2055.

13 Eriksson M, Brown WT, Gordon LB, Glynn MW, Singer J, Scott L, Erdos MR, Robbins CM, Moses TY, Berglund P, Dutra A, Pak E, Durkin S, Csoka AB, Boehnke M, Glover TW, Collins FS. Recurrent de novo point mutations in lamin A cause Hutchinson-Gilford progeria syndrome. Nature 2003;423:293-8.

14 Hutchison CJ. Lamins: building blocks or regulators of gene expression? Nat Rev Mol Cell Biol 2003;3:848-58.

15 Mounkes L, Kozlov S, Burke B, Stewart CL. The laminopathies: nuclear structure meets disease. Curr Opin Genet Dev 2003;13:223-30.

16 Yu CE, Oshima J, Fu YH, Wiijsman EM, Hisama F, Alisch R, Matthews S, Nakura J, Miki T, Ouais S, Martin GM, Mulligan J, Schellenberg GD. Positional cloning of the Werner's syndrome gene. Science 1996;272:258-62.

17 Chen L, Lee L, Kudlow BA, Dos Santos HG, Sletvold O, Shafeghati Y, Botha EG, Garg A, Hanson NB, Martin GM, Mian IS, Kennedy BK, Oshima J. LMNA mutations in atypical Werner's syndrome. Lancet 2003;362:440-5.

18 Pallotta R, Morgese G. Mandibuloacral dysplasia: a rare progeroid syndrome. Two brothers confirm autosomal recessive inheritance. Clin Genet 1984; 26: 133-8.

$19 \mathrm{Ng} \mathrm{D}$, Stratakis CA. Premature adrenal cortical dysfunction in mandibuloacral dysplasia: a progeroid-like syndrome. Am J Med Genet 2000;95:293-5.
20 Novelli G, Muchir A, Sangiuolo F, Helbling-Leclerc A, D'Apice MR, Massart C, Capon F, Sbraccia P, Federici M, Lauro R, Tudisco C, Pallotta R, Scarano G, Dallapiccola B, Merlini L, Bonne G. Mandibuloacral dysplasia is caused by a mutation in LMNA-encoding lamin A/C. Am J Hum Genet 2002;71:426-31.

21 Cao H, Hegele RA. Nuclear lamin A/C R482Q mutation in Canadian kindreds with Dunnigan-type familial partial lipodystrophy. Hum Mol Genet 2000:9:109-12.

22 Genschel J, Bochow B, Kuepferling S, Ewert R, Hetzer R, Lochs H, Schmidt H. A R644C mutation within lamin $A$ extends the mutations causing dilated cardiomyopathy. Hum Mutat 2001;17:154.

23 Agarwal AK, Fryns JP, Auchus RJ, Garg A. Zinc metalloproteinase, ZMPSTE24, is mutated in mandibuloacral dysplasia. Hum Mol Genet 2003; 12:1995-2001

24 Kilic F, Dalton MB, Burrell SK, Mayer JP, Patterson SD, Sinensky M. In vitro assay and characterization of the farnesylation-dependent prelamin $A$ endoprotease. J Biol Chem 1997;272:5298-304.

25 Arbustini E, Pilotto A, Repetto A, Grasso M, Negri A, Diegoli M, Campana C, Scelsi L, Baldini E, Gavazzi A, Tavazzi L. Autosomal dominant dilated cardiomyopathy with atrioventricular block: a lamin A/C defect-related disease. J Am Coll Cardiol 2002;39:981-90.

26 Taylor MR, Fain PR, Sinagra G, Robinson ML, Robertson AD, Carniel E, Di Lenarda A, Bohlmeyer TJ, Ferguson DA, Brodsky GL, Boucek MM, Lascor J, Moss AC, Li WL, Stetler GL, Muntoni F, Bristow MR, Mestroni L, Familial Dilated Cardiomyopathy Registry Research Group. Natural history of dilated cardiomyopathy due to lamin A/C gene mutations. J Am Coll Cardiol 2003:41:771-80.

27 Muchir A, Bonne G, van der Kooi AJ, van Meegen M, Baas F, Bolhuis PA, de Visser $M$, Schwartz $K$. Identification of mutations in the gene encoding lamins $\mathrm{A} / \mathrm{C}$ in autosomal dominant limb girdle muscular dystrophy with atrioventricular conduction disturbances (LGMDIB). Hum Mol Genet 2003;9:1453-9.

28 Brown CA, Lanning RW, McKinney KQ, Salvino AR, Cherniske E, Crowe CA, Darras BT, Gominak S, Greenberg CR, Grosmann C, Heydemann P, Mendell JR, Pober BR, Sasaki T, Shapiro F, Simpson DA, Suchowersky O, Spence JE. Novel and recurrent mutations in lamin $A / C$ in patients with Emery-Dreifuss muscular dystrophy. Am J Med Genet 2001;102:359-67.

29 Caux F, Dubosclard E, Lascols O, Buendia B, Chazouilleres O, Cohen A, Courvalin JC, Laroche L, Capeau J, Vigouroux C, Christin-Maitre S. A new clinical condition linked to a novel mutation in lamins $A$ and $C$ with generalized lipoatrophy, insulin-resistant diabetes, disseminated leukomelanodermic papules, liver steatosis, and cardiomyopathy. J Clin Endocrinol Metab 2003:88:1006-13.

30 Burke B, Stewart $\mathrm{CL}$. Life at the edge: the nuclear envelope and human disease. Nat Rev Mol Cell Biol 2002;3:575-85.

31 Gerace L, Blobel G. The nuclear envelope lamina is reversibly depolymerized during mitosis. Cell 1980;19:277-87.

32 Spann TP, Moir RD, Goldman AE, Stick R, Goldman RD. Disruption of nuclear lamin organization alters the distribution of replication factors and inhibits DNA synthesis. J Cell Biol 1997;136:1201-12.

33 Ozaki T, Saijo M, Murakami K, Enomoto H, Taya Y, Sakiyama S. Complex formation between lamin $A$ and the retinoblastoma gene product: identification of the domain on lamin A required for its interaction. Oncogene 1994;9:2649-53.

34 Mancini MA, Shan B, Nickerson J, Penman AS, Lee WH. The retinoblastoma gene product is a cell cycle-dependent, nuclear matrix-associated protein. Proc Natl Acad Sci U S A 1994;91:418-22.

35 Yamasaki L. Role of the Rb tumor suppressor in cancer. Cancer Treat Res 2003;115:209-39.

36 Spann TP, Goldman AE, Wang C, Huang S, Goldman RD. Alteration of nuclear lamin organization inhibits RNA polymerase II-dependent transcription. J Cell Biol 2002;156:603-8. 